\title{
Short Communication Risk of Kaposi's sarcoma and of other cancers in Italian renal transplant patients
}

\author{
D Serraino*,I, P Piselli', C Angeletti', E Minetti ${ }^{2}$, A Pozzetto ${ }^{3}$, G Civati ${ }^{2}$, S Bellelli', F Farchi ${ }^{4}$, F Citterio ${ }^{3}$, \\ G Rezza $^{4}$, S Franceschi ${ }^{5}$ and $\mathbf{G}$ Busnach $^{2}$ for the Immunosuppression and Cancer Study Group \\ 'Dip. Epidemiologia, INMI L Spallanzani, Via Portunese 292, 001 49, Rome, Italy; ${ }^{2}$ Unità Nefrologia, Dialisi \& Terapia Trapianto Renale, Osp Niguarda \\ Ca' Granda, Piazza Ospedale Maggiore 3, 20162 , Milan, Italy; ' Clinica Chirurgica, Univ Cattolica Sacro Cuore, Policinico 'A. Gemelli', Largo A. Gemelli 8, \\ 00168 Rome, Italy; ${ }^{4}$ Dip Malattie Infettive, Istituto Superiore di Sanità, Viale Regina Elena 292, 00161 Rome, Italy; International Agency for Research on \\ Cancer, 150 cours Albert Thomas, 69372 Lyon cedex 08, France
}

\begin{abstract}
A follow-up study of I 844 renal transplant patients in Italy showed a I I 3-fold increased risk for Kaposi's sarcoma. Kaposi's sarcoma risk was higher in persons born in southern than in northern Italy. Significant increases were also observed for cancers of the lip, liver, kidney and for non-Hodgkin's lymphoma.

British Journal of Cancer (2005) 92, 572-575. doi:I0.I038/sj.bjc.6602346 www.bjcancer.com

Published online 25 January 2005

(c) 2005 Cancer Research UK
\end{abstract}

Keywords: renal transplant; cancer risk; Kaposi's sarcoma; liver cancer; Italy

Renal transplant patients experience higher rates of cancer, particularly virus-related cancers, than the general population. The overall cancer risk is three- to four-fold elevated, but some specific cancers show greater increases (Kinlen, 1992). For nonmelanoma skin cancers and lip cancer, the relative risks are increased 10- to 60-fold (Kinlen et al, 1979; Birkeland et al, 1995; Adami et al, 2003), while the excess of non-Hodgkin's lymphoma (NHL) is about five- to 10-fold (Hoshida et al, 1997; Birkeland et al, 2000; Adami et al, 2003). Kaposi's sarcoma (KS) has been frequently reported in transplant patients in the United States (Penn, 2000), in the Middle East (Qunibi et al, 1988) and in Italy (Montagnino et al, 1996; Pedotti et al, 2003), but the excess risk has not been closely quantified. No increased risk of KS has been reported in transplant patients from the Nordic countries (Birkeland et al, 1995, 2000; Adami et al, 2003), or Japan (Hoshida et al, 1997).

The prevalence of infection with KS-associated herpesvirus (i.e., human Herpesvirus type 8 (HHV-8)) (Whitby et al, 1998; Serraino et al, 2000; Vitale et al, 2001) and the incidence of classic KS (Franceschi and Geddes, 1995; Dal Maso et al, 2004) are relatively high in Italy, particularly in the South. The aim of this study was to quantify the excess of KS risk, to identify factors associated with KS occurrence, and also to define the spectrum of cancers associated with immunosuppression in patients from two major Italian transplant centres.

\section{MATERIALS AND METHODS}

Anonymous information was collected on 1844 patients resident in different parts of Italy and transplanted in northern (Milan) or central Italy (Rome). Of these, 1340 received their transplants at

*Correspondence: Dr D Serraino; E-mail: serraino@inmi.it

Received 29 September 2004; revised 17 November 2004; accepted 24 November 2004; published online 25 January 2005
Niguarda Hospital, Milan, between 1972 and 2003 and 504 at Policlinico Gemelli Hospital, Rome, between 1970 and 2000. As with other investigations, we excluded patients who survived less than 10 days after transplant, those with a pretransplant history of cancer, or who developed cancer in the 30-day period after transplantation (Adami et al, 2003; Pedotti et al, 2003). Nonmelanoma skin cancers were not evaluated since information on basal cell carcinoma was not recorded and that on squamous cell carcinoma might not have been complete.

Person-years (PY) at cancer risk were measured from the date of first renal transplant and ended upon at tumour diagnosis, death, or date of last follow-up visit, whichever occurred first. For the purposes of this analysis, periods of graft failure were not considered. For each type of cancer observed, the expected number (standardised for sex, age, and area of residence) was computed using incidence rates from all population-based cancer registries of Italy for the 1988-1992 period (Parkin et al, 1997). Standardised incidence ratios (SIRs) were computed for all cancers with at least two observed cases, and were obtained by dividing the number of observed cases by the number of expected cases. Ninety-five percent confidence intervals (CI) of SIRs were determined using the Poisson distribution (Breslow and Day, 1980). Incidence rate ratios (IRRs) and their 95\% CIs, adjusted for sex, age, area of birth, and time since transplant, were computed to assess the association between selected characteristics and KS risk among transplant patients.

\section{RESULTS}

The median age of the 1844 renal transplant patients was 42 years (interquartile range: 31-51 years). In 15940 PY of observation (median follow-up time: 7.0 years), 104 cases of cancer, other than nonmelanoma skin cancers, were diagnosed. Standardised incidence ratios according to cancer type or site, and sex are shown in Table 1. 
Table I Standardised incidence ratio (SIR) of cancer and corresponding 95\% confidence interval (Cl) after renal transplantation, according to cancer site or type and sex (Italy, 1970-2003)

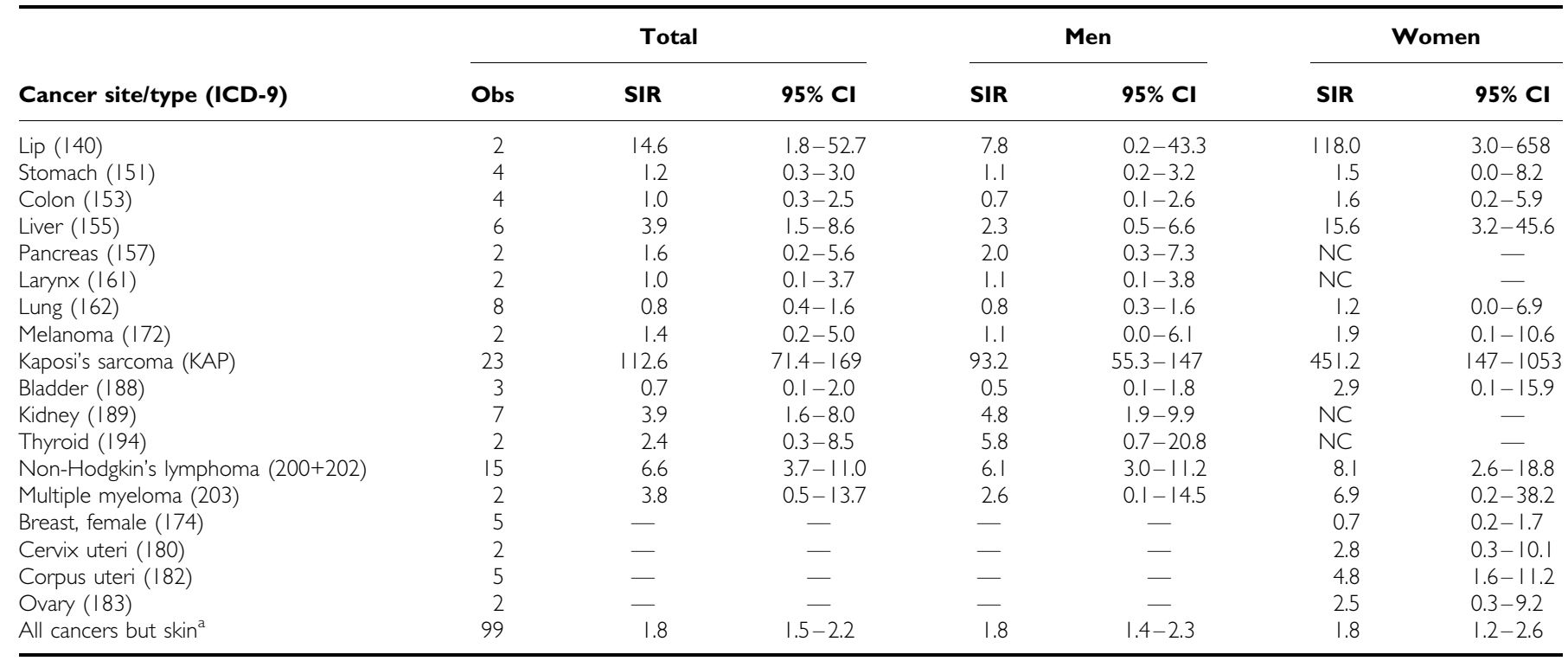

Obs = observed number of cancers. NC = The SIR was not computed because no cancer cases were observed. ${ }^{\mathrm{a}}$ It includes 99 persons with one or more cancer diagnoses (one person had three primary cancers and three persons had two primary cancers). It also includes one case each for: brain, mesothelium, nose or middle ear, prostate, small intestine, testis (seminoma), tonsil and myeloid leukaemia, for a total of 104 cancer diagnoses.

The SIR for all cancers was 1.8 (95\% CI: 1.5-2.2), and was of similar magnitude in the two sexes. The SIR for KS was 112.6 but it was greater among women $(\mathrm{SIR}=451,95 \% \mathrm{CI}: 147-1053)$ than men (SIR $=93,95 \%$ CI: $55-147)$. A 6.6-fold increased SIR (95\% CI: 3.7-11.0) was seen for NHL. Other cancers with significantly elevated SIRs included: carcinomas of the lip (SIR $=14.6$; 95\% CI: 1.8-52.7), liver $(\mathrm{SIR}=3.9 ; 95 \% \quad \mathrm{CI}: 1.5-8.6)$, and kidney $(\mathrm{SIR}=3.9 ; 95 \% \mathrm{CI}: 1.6-8.0)$. The SIRs for lip and liver cancers were more elevated in women than men, whereas the excess risk for native renal cancer was found in men only (Table 1). Standardised incidence ratios for stomach $(\mathrm{SIR}=1.2)$, colon $(\mathrm{SIR}=1.0)$, lung $(\mathrm{SIR}=0.8)$, and female breast cancers $(\mathrm{SIR}=0.7)$ 0.7 ) were close to unity (Table 1$)$.

Among renal transplant patients, KS was more frequent (IRR $=3.0,95 \%$ CI: $1.1-8.5)$ in persons aged 50 years or older at transplant than in those younger than 40. Kaposi's sarcoma was nonsignificantly more common in men than in women, whereas it was nearly six-fold more frequent (95\% CI: 1.6-19.7) in patients born in southern Italy, as compared to those born in northern Italy (Table 2). A strong inverse association emerged between KS occurrence and time since renal transplant. In the first year following transplant, KS was 4.5 -fold more frequent (95\% CI: $1.6-$ 12.2) than after 4 or more years (Table 2).

Most of these 1844 patients $(87 \%)$ received their transplant after cyclosporin came into widespread use (from 1983 onwards), and one-third after the introduction of the newer immunosuppressive drugs (from 1997 onwards). All 23 KS cases were diagnosed in 1983 or later inpatients who were treated with cyclosporincontaining regimens. No significant difference in KS IRRs was seen according to the calendar period of transplant (Table 2).

\section{DISCUSSION}

Our study provides estimates of cancer incidence for renal transplant recipients in northern or central Italy and IRRs for KS. The overall increase in cancer risk we found $(1.8$-fold) is somewhat lower than that reported from previous investigations in transplant patients (Kinlen et al, 1979; Birkeland et al, 1995; Hoshida et al, 1997; Adami et al, 2003), but the exclusion in our analysis of nonmelanoma skin cancers explains a large part of this difference.

With respect to the increased risks for NHL and renal cancer, our results agree with previous investigations (Kinlen, 1992; Birkeland et al, 1995; Adami et al, 2003). It is noteworthy that all cases of renal cancer in this study involved the native kidney, a distinction not mentioned in previous studies. The quantified high risk of KS, particularly in women, and the peak in KS risk in the first year following transplant are new findings. The short induction period between transplant and KS diagnosis suggests that KS development in transplant patients is associated with a rapid re-activation of latent HHV-8 infection (Andreoni et al, 2001; Cannon et al, 2003). The investigation of geographical factors confirmed a higher (about six-fold) KS risk for individuals born in the South of Italy, as compared to those born in the North (Geddes et al, 1995; Dal Maso et al, 2004). On account of massive South-toNorth migration in Italy in the last decades, $44.3 \%$ of our study patients born in the South lived in the North at time of transplant. The KS incidence rate among renal transplant recipients born and resident in the South (i.e., 24.16 per $10000 \mathrm{PY}$ ) was about five-fold higher than that among those born and resident in the North (i.e., 4.62 per $10000 \mathrm{PY}$ ) (data not shown in tables). Moreover, KS incidence among patients who were born in the South, but lived in the North, was similar to that of patients who were born and resident in the South (i.e., 24.70 per $10000 \mathrm{PY}$ ). Information on age at migration was not available in this study, but the stronger association of KS with place of birth than with area of living suggests that acquisition of HHV-8 occurs early in life.

This study also revealed that renal transplant patients in Italy have a four-fold increased risk of liver cancer, an excess risk not generally seen in transplant patients elsewhere (Kinlen, 1992; Birkeland et al, 1995; Adami et al, 2003). In Italy, mortality rates for liver cancer (La Vecchia et al, 2000) and the prevalence of infection with hepatitis $B$ virus and/or with hepatitis $C$ virus 
Table 2 Incidence rate ratio (IRR) for Kaposi's sarcoma and corresponding 95\% confidence interval (Cl) after renal transplantation according to selected characteristics (Italy, 1970-2003)

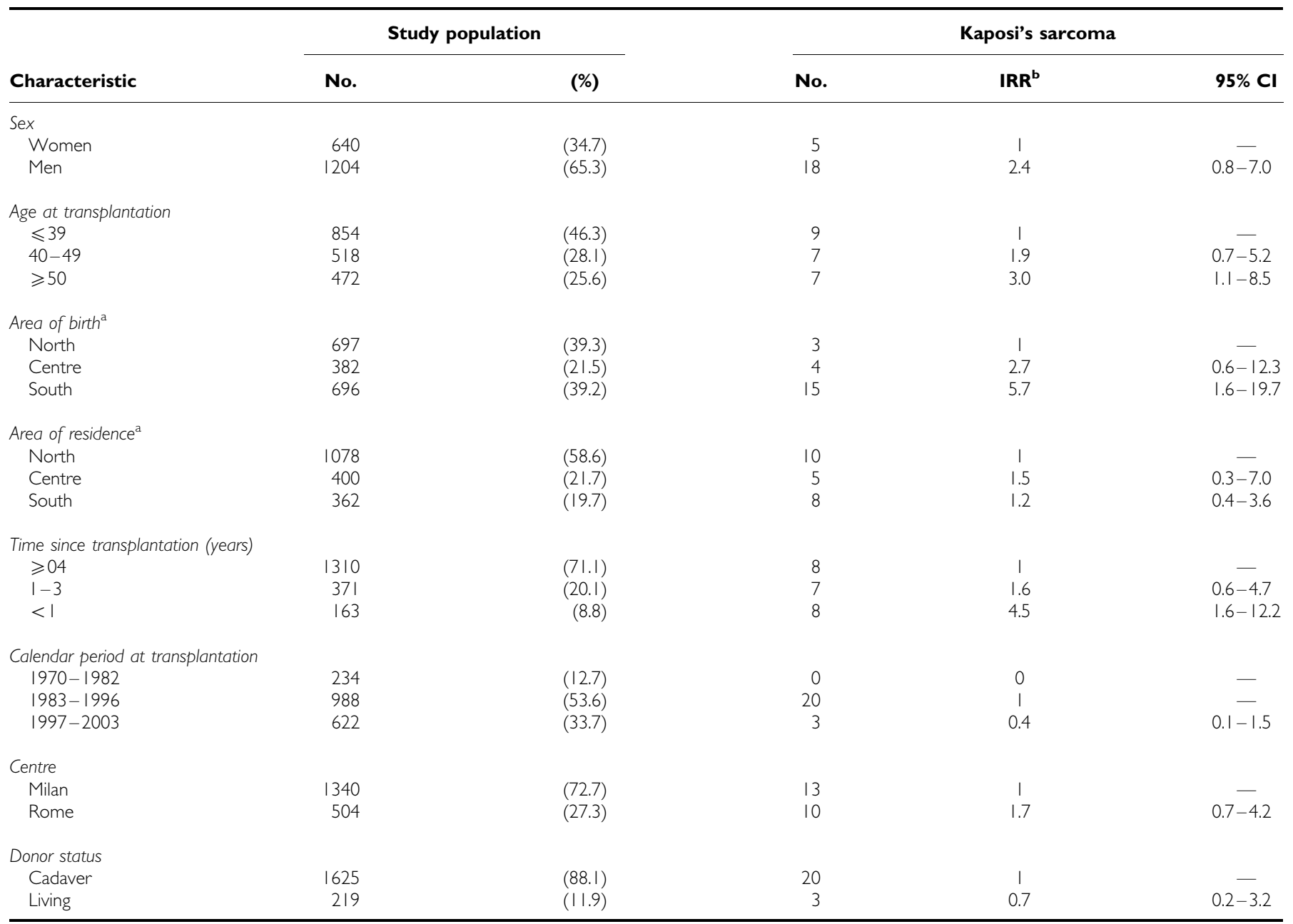

aThe sum does not add up to the total because of missing values. 'IRR adjusted for sex, age at transplantation, area of birth, and time since transplantation.

among dialysis patients are high (Petrosillo et al, 1993; Fissell et al, 2004). The higher SIR for liver cancer found in our study than elsewhere may also be related to the fact that infection with hepatitis $\mathrm{C}$ virus in the recipient is not generally considered a contraindication for renal transplant in Italy.

In conclusion, our findings in patients who underwent renal transplantation in northern or central Italy provide further evidence of the strong association between organ transplant and virus-related cancers. Our observations on post-transplant KS confirm the need for HHV-8 screening protocols and for guide-

\section{REFERENCES}

Adami J, Gabel H, Lindelof B, Ekstrom K, Rydh B, Glimelius B, Ekbom A, Adami HO, Granath F (2003) Cancer risk following organ transplantation: a nationwide cohort study in Sweden. Br J Cancer 89: 1221-1227

Andreoni M, Goletti D, Pezzotti P, Pozzetto A, Monini P, Sarmati L, Farchi F, Tisone G, Piazza A, Pisani F, Angelico M, Leone P, Citterio F, Ensoli B, Rezza G (2001) Prevalence, incidence and correlates of HHV-8/KSHV infection and Kaposi's sarcoma in renal and liver transplant recipients. $J$ Infect 43: 195 - 199

Birkeland SA, Lokkegaard H, Storm HH (2000) Cancer risk in patients on dialysis and after renal transplantation. Lancet 355: 1886-1887 lines on the clinical management of HHV-8 infection in transplant centres, at least in areas endemic for KS (Serraino et al, 2005).

\section{ACKNOWLEDGEMENTS}

This study was supported by the Istituto Superiore di Sanità, Programma di Ricerca Nazionale sull'AIDS, grant no. 20D.13, the Ministero della Sanità, Ricerca Finalizzata 2002 RF 02.139 and the Programma di Ricerca Corrente IRCCS Spallanzani.

Birkeland SA, Storm HH, Lamm LU, Barlow L, Blohme I, Forsberg B, Eklund B, Fjeldborg O, Friedberg M, Frodin L, Glattre E, Halvorsen S, Holm NV, Jakobsen A, Jørgensen HE, Ladefooed J, Lindholm T, Lundgren G, Pukkala E (1995) Cancer risk after renal transplantation in the Nordic countries, 1964-1986. Int J Cancer 60: 183-189

Breslow NE, Day NE (1980) Statistical Methods in Cancer Research. Vol 1 The Analysis of Case-Control Studies. IARC Scientific Publications No. 32. Lyon: IARC Press

Cannon MJ, Laney AS, Pellett PE (2003) Human herpesvirus 8: current issues. Clin Infect Dis 37: $82-87$ 
Dal Maso L, Polesel J, Ascoli V, Zambon P, Budroni M, Ferretti S, Tumino R, Tagliabue G, Patriarca S, Federico M, Vercelli M, Giacomin A, Vicario G, Bellu F, Falcini F, Crocetti E, De Lisi V, Vitarelli S, Piffer S, Stracci F, Serraino D, Rezza G, Franceschi S (2004) Classic Kaposi's sarcoma in Italy, $1985-1998$. Br J Cancer, in press

Fissell RB, Bragg-Gresham JL, Woods JD, Jadoul M, Gillespie B, Hedderwick SA, Rayner HC, Greenwood RN, Akiba T, Young EW (2004) Patterns of hepatitis $\mathrm{C}$ prevalence and seroconversion in hemodialysis units from three continents: the DOPPS. Kidney Int 65: 2335-2342

Franceschi S, Geddes M (1995) Epidemiology of classic Kaposi's sarcoma, with special reference to Mediterranean population. Tumori 81: $308-314$

Geddes M, Franceschi S, Balzi D, Arniani S, Gafa L, Zanetti R (1995) Birthplace and classic Kaposi's sarcoma in Italy. J Natl Cancer Inst 87: 1015- 1017

Hoshida Y, Tsukuma H, Yasunaga Y, Xu N, Fujita MQ, Satoh T, Ichikawa Y, Kurihara K, Imanishi M, Matsuno T, Aozasa K (1997) Cancer risk after renal transplantation in Japan. Int J Cancer 71: 517-520

Kinlen LJ (1992) Immunosupression and cancer. In Mechanisms of Carcinogenesis in Risk Identification Vainio H, Magee P, McGregor DB, McMichael AJ (eds) IARC Scientific Publications No. 116, pp 237-253. Lyon: IARC Press

Kinlen LJ, Sheil AG, Peto J, Doll R (1979) Collaborative United Kingdom Australasian study of cancer in patients treated with immunosuppressive drugs. $\mathrm{Br}$ Med J 2: $1461-1466$

La Vecchia C, Lucchini F, Franceschi S, Negri E, Levi F (2000) Trends in mortality from primary liver cancer in Europe. Eur J Cancer 36: 909-915

Montagnino G, Lorca E, Tarantino A, Bencini P, Aroldi A, Cesana B, Braga M, Lonati F, Ponticelli C (1996) Cancer incidence in 854 kidney transplant recipients from a single institution: comparison with normal population and with patients under dialytic treatment. Clin Transplant 10: $461-469$

\section{Appendix A}

\section{Other members of the Immunosuppression and Cancer Study Group}

A Navarra, M Scuderi, P Vanacore (INMI 'L Spallanzani' IRCCS, Rome, Italy); B Longo, M Dorrucci (Istituto Superiore di Sanità, Rome, Italy); MP Carrieri (INSERM U379, Marseille, France); C Pradier (Departement de Santé Publique, Hopital de l'Archet, Nice,
Parkin DM, Whelan SL, Ferlay J, Raymond L, Young J eds (1997) Cancer Incidence in Five Continents, Vol VII. IARC Scientific Publications No. 143. Lyon: IARC Press

Pedotti P, Cardillo M, Rossini G, Arcuri V, Boschiero L, Caldara R, Cannella G, Dissegna D, Gotti E, Marchini F, Maresca MC, Montagnino G, Montanaro D, Rigotti P, Sandrini S, Taioli E, Scalamogna M (2003) Incidence of cancer after kidney transplant: results from the North Italy transplant program. Transplantation 76: $1448-1451$

Penn I (2000) Post-transplant malignancy: the role of immunosuppression. Drug Saf 23: $101-113$

Petrosillo N, Puro V, Ippolito G (1993) Prevalence of human immunodeficiency virus, hepatitis $\mathrm{B}$ virus and hepatitis $\mathrm{C}$ virus among dialysis patients. The Italian Multicentric Study on Nosocomial and Occupational Risk of Blood-Borne Infections in Dialysis. Nephron 64: 636-639

Qunibi W, Akhtar M, Sheth K, Ginn HE, Al Furayh O, DeVol EB, Taher S (1988) Kaposi's sarcoma: the most common tumor after renal transplantation in Saudi Arabia. Am J Med 84: 225-232

Serraino D, Bordonaro R, Failla G, De Paoli P, Colina P, Tedeschi RM, Ippolito G (2000) Prevalence of HHV-8 infection among cancer patients in Sicily. Int J Cancer 86: $448-449$

Serraino D, Piselli P, Scuderi M, Gabbrielli F, Venettoni S, Grossi P, Nanni Costa A, Ippolito G (2005) Screening for Human Herpesvirus 8 antibodies in Italian organ transplant centres. Clin Infect Dis 40: 203-205

Vitale F, Briffa DV, Whitby D, Maida I, Gochowska A, Levin A, Romano N, Goedert JJ (2001) Kaposi's sarcoma herpes virus and Kaposi's sarcoma in the elderly populations of 3 Mediterranean islands. Int J Cancer 91: $588-591$

Whitby D, Luppi M, Barozzi P, Boshoff C, Weiss RA, Torelli G (1998) Human Herpesvirus 8 seroprevalence in blood donors and lymphoma patients from different regions of Italy. J Natl Cancer Inst 90: $395-397$

France); ML Broggi, V Colombo, ML Perrino, L Radaelli (Ospedale Niguarda Cà Granda, Milan, Italy); L Dal Maso, J Polesel (Centro di Riferimento Oncologico, IRCCS, Aviano, Italy); M Castagneto (Università Cattolica, Rome, Italy). 